\title{
Análise Exploratória dos Registros de Software do Instituto Nacional da Propriedade Industrial (INPI) de 2018 a 2020
}

\section{Exploratory Analysis of Software Registration of the National Institute of Industrial Property (INPI) from 2018 to 2020}

Felipe Rafael dos Santos Barbosa ${ }^{1}$, Alan Marcel Fernandes de Souza ${ }^{1 *}$, Alyne Marcely

Fernandes de Souza ${ }^{1}$, Polyana Santos Fonseca Nascimento ${ }^{1}$, Alessandra Natasha Alcantara

Barreiros Baganha ${ }^{1}$

\begin{abstract}
RESUMO
O registro de software permite comprovar a autoria diante do Poder Judiciário, servindo como documento comprobatório em relação à pirataria e a cópias não autorizadas. O objetivo deste artigo é analisar os dados mantidos e disponibilizados pelo INPI dos softwares registrados nos anos de 2018 a 2020. Os resultados mostraram que as tecnologias mais utilizadas nos programas registrados condizem com aquelas usadas no mercado de trabalho; que as áreas de conhecimento com mais registros são administração, ciência da informação e indústria e que os tipos de programas com maior número de registros são aplicativos, gerenciadores de informações e ferramentas de apoio. Conclui-se que o registro de software tem sido cada vez mais utilizado por desenvolvedores, empresas e instituições de pesquisa, já que essa é uma forma de proteger o programa criado e disponibilizado, face a alta concorrência deste mercado a nível nacional e até internacional.
\end{abstract}

Palavras-chave: Registro; Software; INPI; Dados; Proteger.

\section{ABSTRACT}

The software registration allows proof of authorship to the Judiciary, serving as a supporting document in relation to piracy and unauthorized copies. The objective of this article is to analyze the data maintained and made available by the INPI of the software registered from 2018 to 2020. The results showed that the technologies most used in the registered programs are in line with those used in the job market; that the areas of knowledge with more records are administration, information science and industry and that the types of programs with the highest number of records are applications, information managers and support tools. It is concluded that software registration has been increasingly used by developers, companies and research institutions, since this is a way of protecting the program created and made available, in the face of high competition in this market at a national and even international level.

Keywords: Registration; Software; INPI; Data; Protecting.

${ }^{1}$ Centro Universitário do Estado do Pará (CESUPA), Belém, Pará, Brasil.

*E-mail: alan.souza@prof.cesupa.br 


\section{INTRODUÇÃO}

A Tecnologia da Informação (TI) é uma área do conhecimento relativamente nova, quando comparada com outras áreas. Porém, é um dos segmentos que mais tem se desenvolvido nos últimos anos (PARADA \& GOLIN, 2018). A TI possui várias subdivisões: redes de computadores, banco de dados, segurança da informação, engenharia de software, desenvolvimento de sistemas e várias outras. O mercado de trabalho em todas as áreas está aquecido: de acordo com ABES (2021), a indústria de tecnologia cresceu quase $23 \%$ e investiu mais de 200 bilhões de reais em 2020. Outra forte evidência é o fato de estar faltando profissionais capacitados para ingressar neste mercado (CARDOSO \& DE DAVID, 2016).

Apple, Amazon e Microsoft são consideradas, nessa ordem, as empresas mais valiosas do mundo, segundo Forbes (2021). Essas multinacionais têm em comum produtos inovadores - na maioria das vezes, softwares - que são utilizados, a todo momento, por milhares de pessoas e por empresas ao redor do planeta, sendo extremamente rentáveis.

$\mathrm{O}$ aquecimento do mercado de TI e a crescente necessidade de automatizar, através de software, tarefas através do computador e/ou dispositivos smarts contribuem para acirrar a concorrência entre as empresas, existindo a probabilidade de aumentar o plágio ou pirataria de software (FERES et al, 2017). Para mitigar esse problema, faz-se primordial registrar o software.

No Brasil, a lei de propriedade intelectual que garante proteção legal e prevê sanções é a Lei 9.609/1998. O artigo 12 desta lei preceitua que quem violar o direito autoral de programa de computador pode incorrer em pena de detenção de seis meses a dois anos ou multa ${ }^{2}$. Se a cópia ilegal for comercializada, a pena pode aumentar para até quatro anos de reclusão e multa ${ }^{3}$.

Na hipótese de um usuário suspeito de estar fazendo uso irregular de programas, é necessário que o autor dos programas provoque o Judiciário, com a interposição de

\footnotetext{
${ }^{2}$ Art. 12. Violar direitos de autor de programa de computador: Pena - detenção de 6 (seis) meses a 2 (dois) anos ou multa.

${ }^{3}$ Art. $12, \S 1^{\circ}$. Se a violação consistir na reprodução, por qualquer meio, de programa de computador, no todo ou em parte, para fins de comércio, sem autorização expressa do autor ou de quem o represente: Pena - Reclusão de 1 (um) a 4 (quatro) anos e multa.
} 
medida cautelar de vistoria, com pedido de liminar inaudita altera pars cumulada com busca e apreensão contra este usuário ${ }^{4}$.

Em caso de venda, exposição para venda, introdução no país, aquisição, ocultação ou ter em depósito, para fins de comércio, original ou cópia de programa de computador, produzido com violação de direito autoral há pena de reclusão de um a quatro anos e multa ${ }^{5}$.

Conforme dito, é necessário que o autor do programa que teve algum desses prejuízos provoque o Judiciário, mediante queixa. A exceção encontra-se quando figura no pólo passivo do prejuízo uma entidade de direito público ou quando em decorrência do ato delituoso, resultar sonegação fiscal, perda de arrecadação tributária ou prática de quaisquer dos crimes contra a ordem tributária ou contra as relações de consumo ${ }^{6}$.

A instituição governamental brasileira que lida, dentre outros tipos de serviços, com o registro de software é o Instituto Nacional da Propriedade Industrial (INPI). Tratase de uma autarquia federal atrelada ao Ministério da Economia que

"tem por finalidade principal executar, no âmbito nacional, as normas que regulam a propriedade industrial, tendo em vista a sua função social, econômica, jurídica e técnica, bem como pronunciar-se quanto à conveniência de assinatura, ratificação e denúncia de convenções, tratados, convênios e acordos sobre propriedade industrial" (BRASIL, 1970).

O estudo desenvolvido por Da Silva (2021) objetivou visualizar dados relacionados a ofertas de bolsas e auxílios pagos pelo CNPq (Conselho Nacional de Desenvolvimento Científico e Tecnológico) de 2002 até 2020, gerando informações gráficas dos dados; também, a classificação das áreas da TI; e ainda, a análise dos dados

\footnotetext{
${ }^{4}$ Art. 14. Independentemente da ação penal, o prejudicado poderá intentar ação para proibir ao infrator a prática do ato incriminado, com cominação de pena pecuniária para o caso de transgressão do preceito. $\S 1^{\circ} \mathrm{A}$ ação de abstenção de prática de ato poderá ser cumulada com a de perdas e danos pelos prejuízos decorrentes da infração.

$\S 2^{\circ}$ Independentemente de ação cautelar preparatória, o juiz poderá conceder medida liminar proibindo ao infrator a prática do ato incriminado, nos termos deste artigo.

$\S 3^{\circ}$ Nos procedimentos cíveis, as medidas cautelares de busca e apreensão observarão o disposto no artigo anterior.

${ }^{5}$ Art. $12, \S 2^{\circ}$. Na mesma pena do parágrafo anterior incorre quem quem vende, expõe à venda, introduz no país, adquire, oculta ou tem em depósito, para fins de comércio, original ou cópia de programa de computador, produzido com violação de direito autoral.

${ }^{6}$ Art. 12. Violar direitos de autor de programa de computador:

$\S 3^{\circ}$. Nos crimes previstos neste artigo, somente se procede mediante queixa, salvo:

I - quando praticados em prejuízo de entidade de direito público, autarquia, empresa pública, sociedade de economia mista ou fundação instituída pelo poder público.

II - quando, em decorrência de ato delituoso, resultar sonegação fiscal, perda de arrecadação tributária ou prática de quaisquer dos crimes contra a ordem tributária ou contra as relações de consumo.
} 
de investimentos em pesquisas ao longo do tempo, abrangendo o cenário políticoeconômico que justifiquem tais investimentos. Os dados foram extraídos do Portal de Transparência do Governo Federal.

Cordeiro \& Cassiano (2018) realizaram uma análise exploratória de dados com a finalidade de mostrar o panorama dos cursos de graduação, vinculados às Instituições Federais de Ensino Superior (IFES), identificando os eixos estruturantes no que tange às áreas de conhecimento abordadas em suas matrizes curriculares. No âmbito da abordagem quantitativa, primeiramente, com base na matriz curricular do curso em cada IFES, obteve-se uma relação de todas disciplinas ofertadas, as quais tiveram seus nomes padronizados, de acordo com compatibilidade de suas ementas. A partir disso, foi realizada uma classificação de cada disciplina em suas respectivas áreas de conhecimento, conforme tabela de áreas de conhecimento da CAPES (Coordenação de Aperfeiçoamento de Pessoal de Nível Superior). Essa classificação apresenta quatro níveis de hierarquização, indo do mais geral ao mais específico, na seguinte ordem: Grande Área, Área do Conhecimento, Subárea e Especialidade.

Com o propósito de introduzir o assunto de propriedade industrial no meio acadêmico brasileiro, dando destaque a área da química e suas diferentes formações, Silva (2017) desenvolveu um guia que explica sobre patentes, requisitos de patenteabilidade, atividade inventiva, aplicação industrial, entre outras informações de suma importância para a composição de uma patente. O trabalho abordou também, particularidades relacionadas sobre patentes na área química. Para que uma patente seja concedida, a invenção deve ser dotada de novidade, atividade inventiva (ou ato inventivo) e aplicação industrial. Logo, pode ser observado que a etapa inicial deve ser a etapa de busca de anterioridade, ou seja, a busca para obter informações sobre o estado da técnica, o que já foi protegido e o que já foi divulgado. Tal etapa de busca deve ser realizada, idealmente, antes de iniciar o projeto de pesquisa, para evitar investimentos e gastos desnecessários referentes ao trâmite do pedido de patente junto ao INPI.

De acordo com Almeida (2017), o INPI conta também com registros de patentes na área de produtos naturais relacionados à saúde, que trás como um dos estudos, verificar patentes depositadas por ano, por país no período de 1900 a 2015, como também, verificar o percentual de patentes e ainda verificar as patentes classificadas por tipo de despacho, cuja justificativa baseia-se em, incentivar e alertar aos pesquisadores brasileiros em patentear, mostrar que o cenário brasileiro é propício para pesquisas referentes ao 
patrimônio genético, gerar questionamentos sobre as práticas exploratórias no Brasil, tomar medidas de proteção aos produtos naturais brasileiros frente a exploração por países desenvolvidos, além de constatar as lacunas que facilitam a prática da biopirataria no país.

O banco de dados de registros de software é público e é de fundamental importância conhecê-lo para não incorrer nos problemas mencionados anteriormente, caso haja duplicidade de propriedade industrial já protegida. Além disso, analisando os trabalhos correlatos da literatura supracitados, verifica-se que nenhum leva em conta os registros de software junto ao INPI. Nesse sentido, o objetivo deste artigo é realizar uma análise exploratória dos dados dos programas de computador registrados nos anos de 2018, 2019 e 2020.

A segunda seção deste trabalho compreende a metodologia empregada para desenvolvê-lo, a terceira mostra e discute os resultados e a quarta traz as conclusões e trabalhos futuros.

\section{METODOLOGIA}

Os dados utilizados neste estudo são provenientes do Portal de Dados Abertos do Governo Federal (dados.gov.br) e consideram os registros de software realizados nos anos de 2018, 2019 e 2020. O quadro 1 mostra o dicionário da base de dados utilizada.

Quadro 1 - Dicionário da base de dados do INPI referente aos registros de software

\begin{tabular}{|l|l|}
\hline \multicolumn{1}{|c|}{ Nome do campo } & \multicolumn{1}{c|}{ Descrição } \\
\hline numero_registro & Número do registro \\
\hline data_deposito & Data do depósito \\
\hline linguagem & Linguagem \\
\hline campo_aplicacao & Campo de aplicação \\
\hline titulo_programa & Título do programa \\
\hline tipo_programa & Tipo de programa \\
\hline nome_titular & Nome do titular \\
\hline nome_autor & Nome do autor \\
\hline nome_procurador & Nome procurador \\
\hline numero_rpi & Número da RPI \\
\hline data_publicacao_rpi & Data da publicação da RPI \\
\hline numero_despacho & Código do despacho \\
\hline descricao_despacho & Descrição do despacho \\
\hline complemento_despacho & Complemento do despacho \\
\hline \multicolumn{1}{|c|}{ Nome do campo } & \multicolumn{1}{c|}{ Descrição } \\
\hline data_lancamento_programa & Data de lançamento \\
\hline data_protocolo_externo & Data do protocolo externo \\
\hline codigo_sigilo_programa & Código de sigilo do programa \\
\hline
\end{tabular}

Fonte: Autores (2022). 
Esses dados são disponibilizados em formato CSV (comma-separated values). Utilizou-se a metodologia ETL (extract, transform, load) para facilitar a análise exploratória. Após o download dos dados, unificou-se os arquivos CSV, que foram transformados e carregados em um banco de dados relacional MySQL com o objetivo de usar SQL (structed query language) que permite extrair conhecimento de maneira consistente e rápida. A última etapa foi construir gráficos, com o auxílio da ferramenta Google Sheets, para concretizar as análises. A figura 1 ilustra o passo a passo da metodologia empregada.

Figura 1 - Diagrama do fluxo ETL

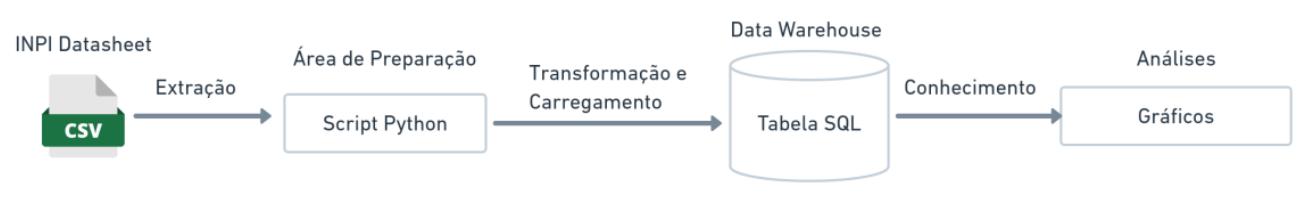

Fonte: Autores (2022).

Outra análise realizada foi construir nuvens de palavras para sumarizar dados textuais, tais como: nomes dos titulares do software e títulos dos programas. Ressalta-se que a nuvem de palavras calcula a frequência de cada palavra do banco de dados e, quanto maior for essa frequência, mais destaque a palavra irá aparecer na nuvem.

Os gráficos quantitativos e as nuvens de palavras geradas nesta análise estão dispostos na próxima seção deste artigo.

\section{RESULTADOS E DISCUSSÕES}

Inicia-se a exploração dos dados observando o quantitativo de registros realizados por ano. Através do gráfico da figura 2, vê-se que entre os anos 2018 e 2019 houve um aumento de quase $20 \%$ nos registros de software e que entre 2019 e 2020 ocorreu ligeira queda de aproximadamente $3 \%$ na referida quantidade. Essa queda pode estar associada à pandemia do Covid-19, que atrasou muitos projetos, seja por impedimentos de saúde dos desenvolvedores ou por redução no financiamento dos projetos. 
Figura 2 - Expedição do registro de software por ano

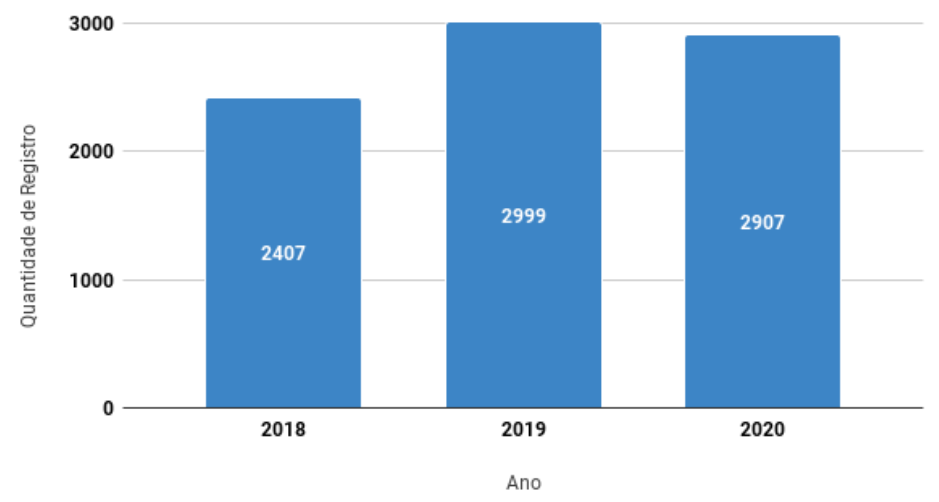

Fonte: Autores (2022).

Outra análise realizada foi investigar o quantitativo das tecnologias (linguagens de programação) utilizadas nos registros efetuados. O Javascript, o HTML (HyperText Markup Language), o CSS (Cascade Style Sheet) e o PHP (Hypertext Preprocessor) são tecnologias que fazem parte das primeiras posições, conforme mostra a figura 3. Esse predomínio demonstra que a maioria dos softwares registrados levam em conta projetos web, ou seja, aqueles que funcionam através de um servidor que provê serviços para clientes. Percebe-se também, que o SQL e o MySQL também estão dentro das vinte tecnologias mais usadas, indicando que a maioria dos softwares lidam com banco de dados.

Figura 3 - As vinte tecnologias mais utilizadas nos softwares registrados

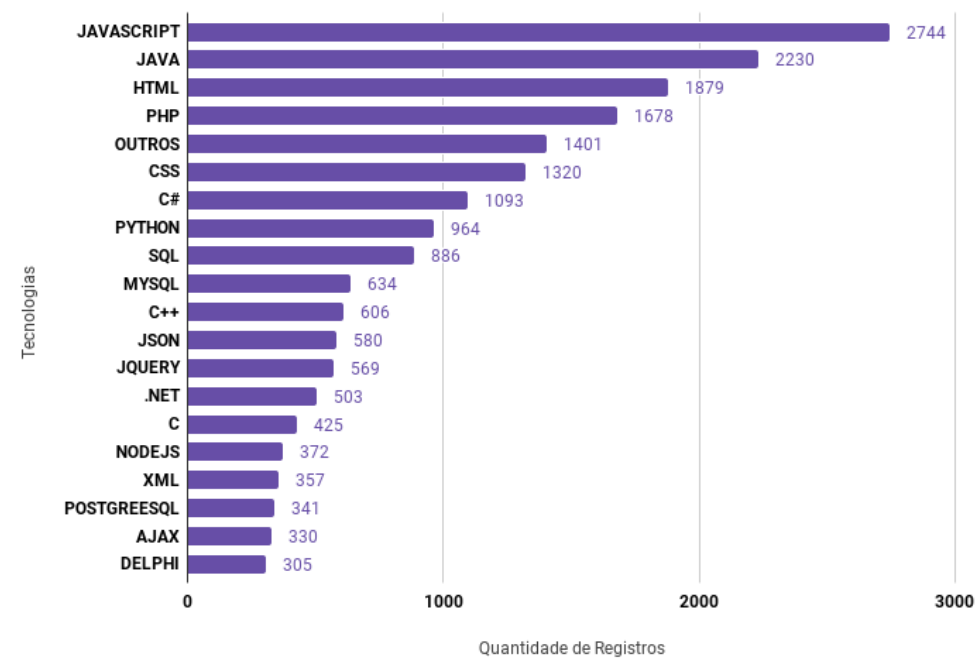

Fonte: Autores (2022).

Por outro lado, as vinte tecnologias menos utilizadas estão listadas no gráfico da figura 4. Nota-se que a maioria delas, como ADVPL, Lotus, LISP e Quick Basic são, atualmente, consideradas ultrapassadas e que já não atendem às necessidades empresariais da atualidade, visto que, há tecnologias mais recentes a serem exploradas e 
que garantem maior suporte, tendo uma comunidade mais ativa e que é ensinada em cursos superiores pelas instituições de ensino do Brasil e do exterior.

Figura 4 - As vinte tecnologias mais utilizadas nos softwares registrados

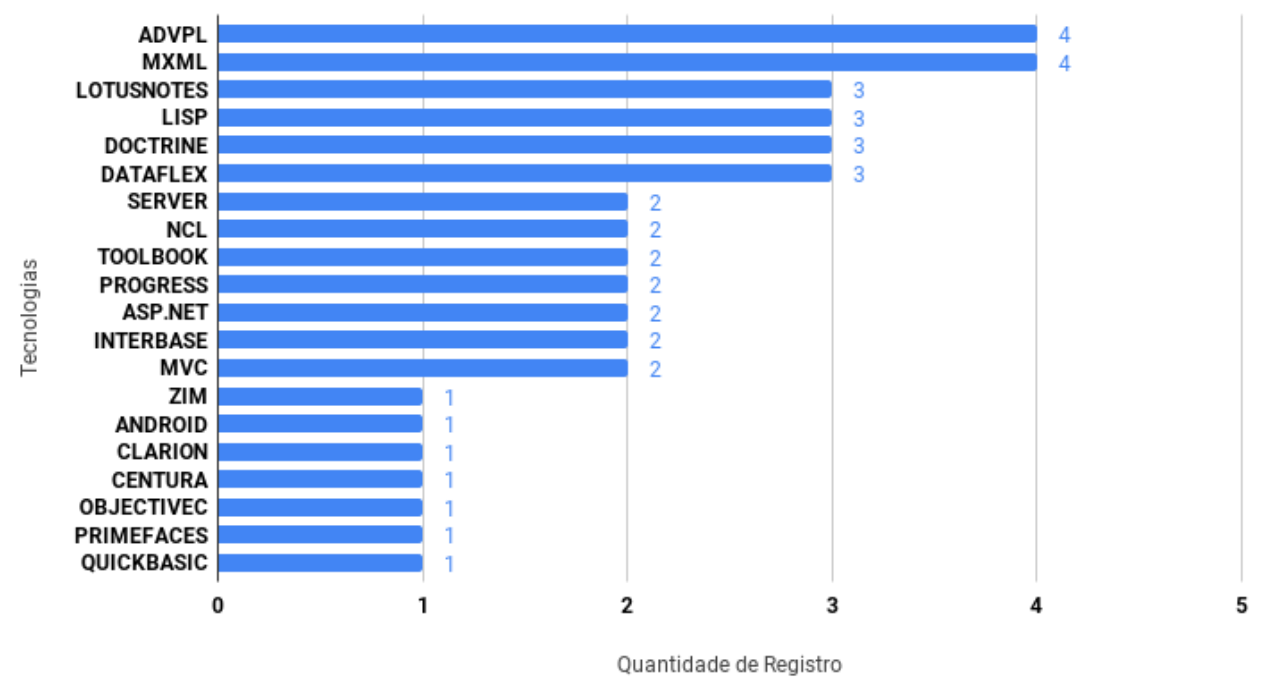

Fonte: Autores (2022).

Levando em conta os campos de aplicação cadastrados no ato dos registros, verifica-se, por intermédio da figura 5, que o campo mais frequente é o AD-01 (Função Administrativa). Esses registros de aplicação estão relacionados a área administrativa de softwares que tem por função o desenvolvimento organizacional e desburocratização e representam 3,75\% das informações contidas na base de dados, considerando todos os anos. Na segunda posição, estão os sistemas focados na área da informação, tais sistemas classificados como IF-10 (Genérico) são responsáveis em processamento de dados, enquanto os IF-07 (Ciência da Informação), que ocupam a terceira posição, possuem como descrição "sistema de informação, rede de informação, teoria da informação e fluxo de informação". Ocupando a última posição, está o campo de aplicação TC-02 (Sistema de Telecomunicação) que é responsável pelas áreas das telecomunicações. Nota-se que setores importantes da economia também estão presentes nessa lista principal: indústria, educação e saúde. 
Figura 5 - Os vinte campos de aplicação mais frequentes nos softwares registrados

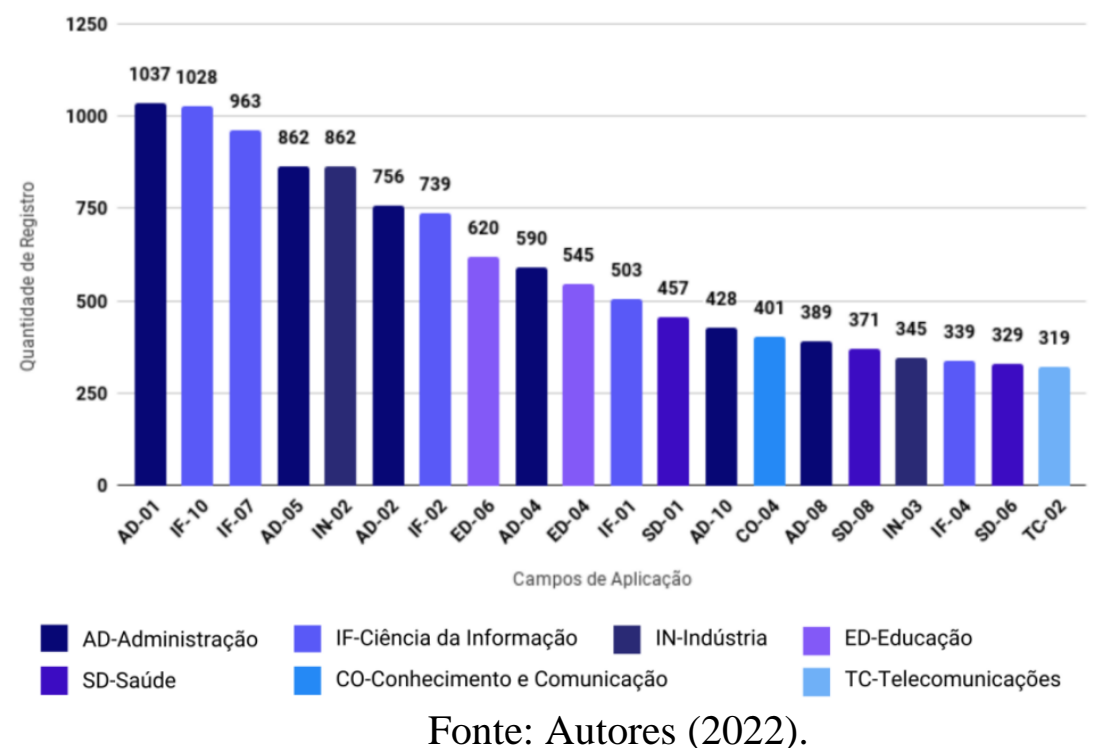

Analisando a característica tipos de programas (figura 6), a grande maioria é do tipo AP-01 (Aplicativos). Em seguida, tem-se programas do tipo GI-01 (Gerenciador de Informações) que são sistemas cujo papel é gerenciar informações de diversas esferas do conhecimento. Em terceiro lugar, apresentam-se os softwares AP-03 (Controle) que são programas de controle de processos e, em último lugar, estão os programas do tipo GI-07 (Organização e Manutenção de Arquivos) responsáveis por organizar, tratar e realizar manutenção em arquivos de diversos contextos. Ressalta-se ainda que ferramentas de apoio, inteligência artificial e simulação e modelagem também possuem posições de destaque. 
Figura 6 - Os vinte tipos mais frequentes de softwares registrados

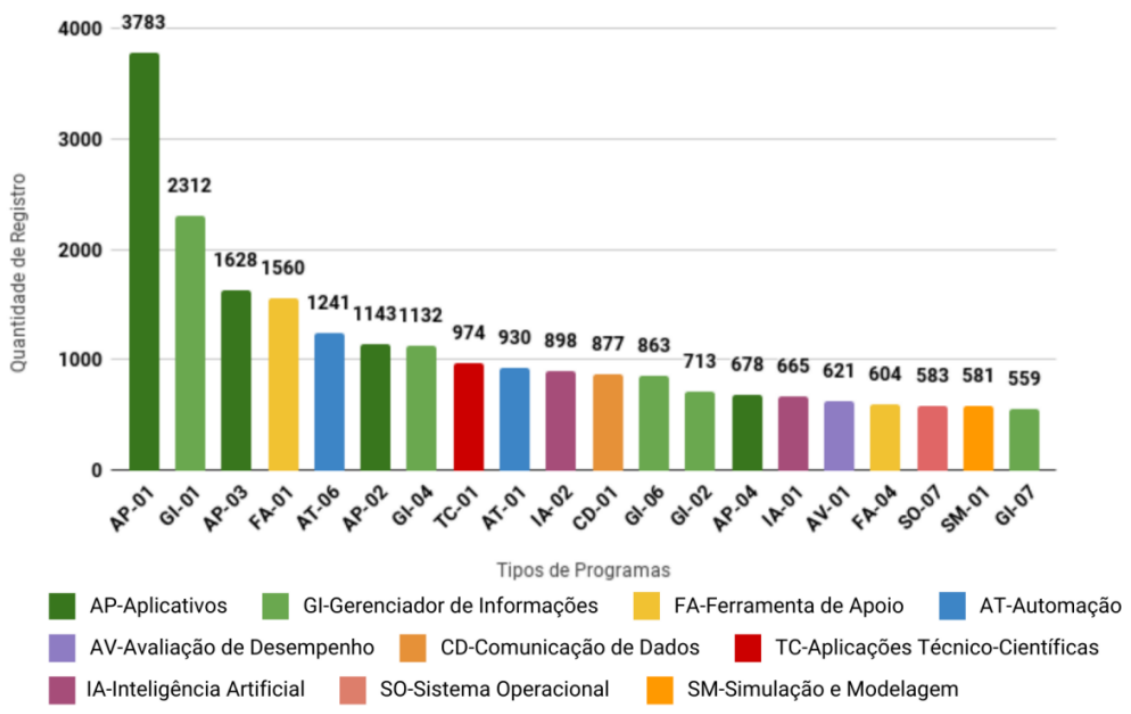

Fonte: Autores (2022).

É importante destacar que é possível escolher mais de uma linguagem de programação, de um campo de aplicação e de um tipo de programa no preenchimento de formulário de registro de software enviado para o INPI.

Explorando os títulos dos programas registrados, apresenta-se a nuvem de palavras da figura 7. Nota-se que a maior frequência calculada é a palavra "Sistema", seguida por, "Gestão", "Software", "Aplicativo" e "Plataforma", sendo coerente com os vinte campos de aplicação e vinte tipos de registro de software das análises anteriores.

Figura 7 - Nuvem de palavras dos títulos dos softwares registrados

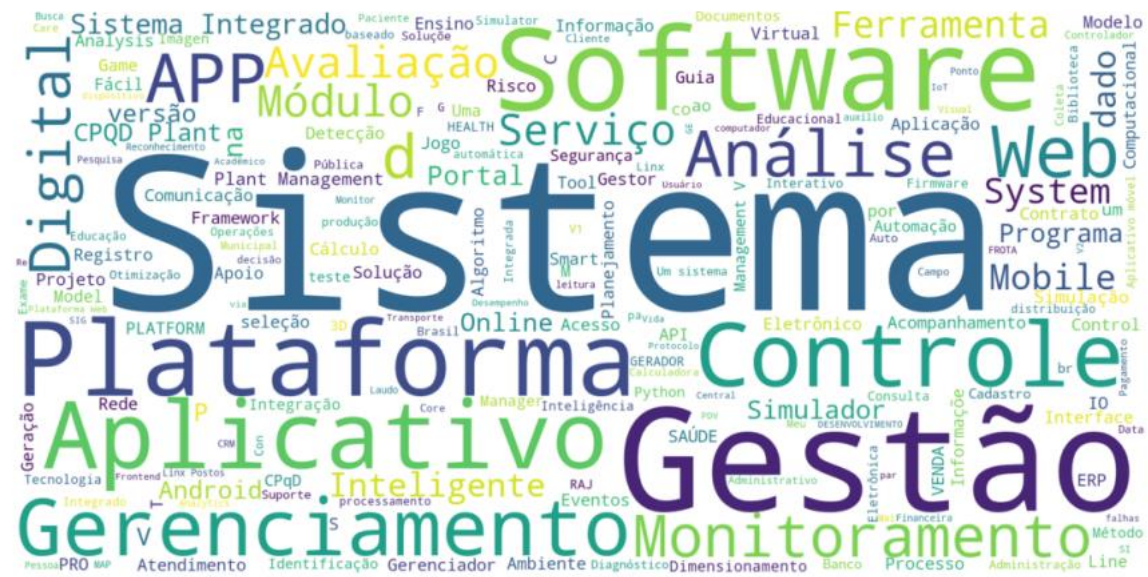

Fonte: Autores (2022).

Uma outra nuvem de palavras construída considera os nomes cadastrados como titulares dos softwares (figura 8). Percebe-se a grande presença da palavra "Tecnologia" e de expressões associadas às instituições de ensino, tais como: "Instituto Federal", "Universidade Federal" e "Universidade Estadual”. Isso é um indício que a maioria dos 
registros de softwares são frutos de trabalhos acadêmicos e/ou de projetos de pesquisa. Entretanto, empresas do ramo da tecnologia da informação (mercado de trabalho) também costumam registrar os seus softwares. Isso se confirma através das palavras "Consultoria", "Soluções", "Software”, "Serviço", por exemplo.

Figura 8 - Nuvem de palavras dos titulares dos softwares registrados

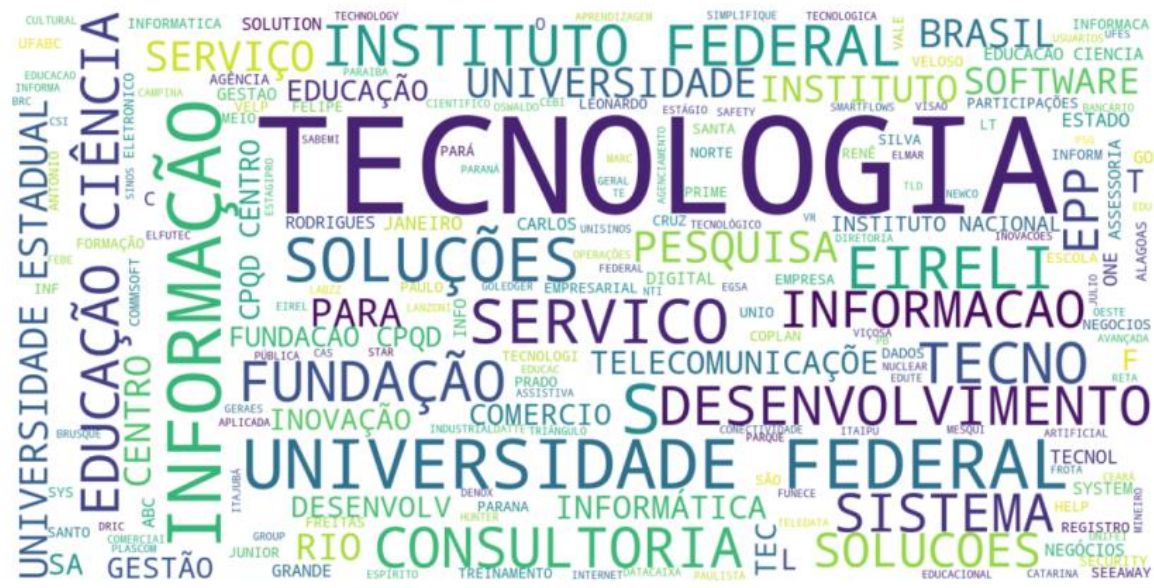

Fonte: Autores (2022).

Outras informações adquiridas através da análise dos dados em tela, referem-se ao quantitativo de titulares, de autores, de linguagens, de campos de aplicação e tipos de programas por registro de software realizado, que estão sumarizadas na tabela 1. Constata-se, em média: que há somente um titular por registro; que há cerca de três autores por registro; que três linguagens de programação são escolhidas; que mais de três campos de atuação são selecionados e que quatro tipos de programas são considerados por registro. É importante destacar que a quantidade de autores pode superar a máxima elencada, isso se dá ao fato de que o campo respectivo está truncado no CSV disponibilizado pelo INPI.

Tabela 1 - Sumário do quantitativo de titulares e de autores por registro de software

\begin{tabular}{l|c|c|c|c}
\hline \multicolumn{1}{c|}{ Campo } & Mínimo & Máximo & Média & Desvio padrão \\
\hline Nomes de titulares & 1 & 8 & 1,30 & 0,75 \\
\hline Nomes de autores & 1 & 11 & 2,74 & 2,06 \\
\hline $\begin{array}{l}\text { Linguagens/ } \\
\text { Tecnologias }\end{array}$ & 1 & 23 & 2,57 & 2,45 \\
\hline Campos de aplicação & 1 & 26 & 3,23 & 3,50 \\
\hline Tipos de programas & 1 & 26 & 4,17 & 4,78 \\
\hline
\end{tabular}

Fonte: Autores (2022). 


\section{CONSIDERAÇÕES FINAIS}

Diante de um cenário de TI cada vez mais competitivo e volátil, faz-se necessário que os desenvolvedores de software (pessoas física ou jurídica) conheçam formas de proteger seus produtos e principalmente saibam características genéricas a respeito de softwares já registrados no INPI. Uma vez ciente dessas informações, explanadas com detalhes neste artigo, é possível assegurar cada vez mais a inovação do ecossistema de TI no Brasil.

Ademais, essas informações são úteis para observar: (1) quais setores do mercado brasileiro estão carentes de soluções tecnológicas; (2) quais tipos de softwares são criados com mais frequência; (3) quais tecnologias são mais usadas, sendo possível investir em capacitação de pessoas para prestar manutenção nos softwares; (4) o quantitativo de titulares e autores.

Como trabalhos futuros, pretende-se criar um painel de controle para visualizar as informações extraídas dos dados em pauta de maneira organizada e centralizada. Além disso, planeja-se realizar a análise exploratória dos registros realizados após 2020, comparando-a com este diagnóstico aqui explorado.

\section{+REFERÊNCIAS}

ABES. Mercado Brasileiro de Software: panorama e tendências em 2021. 1 $1^{\mathrm{a}}$. ed. São Paulo: ABES - Associação Brasileira das Empresas de Software, 2021.

ALMEIDA, L. N. Avaliação do depósito de patentes de produtos naturais em saúde no INPI. 2017. 37 f. Trabalho de conclusão de curso (Graduação em Farmácia) Universidade Federal de Sergipe, Lagarto, Sergipe, 2017.

BRASIL. Lei n. 5.648, de 11 de dezembro de 1970. Cria o Instituto Nacional da Propriedade Industrial e dá outras providências. 1970. Disponível em: <http://www.planalto.gov.br/ccivil_03/leis/15648.htm>. Acesso em: janeiro de 2022.

Lei n. 9.609, de 19 de fevereiro de 1998. Dispõe sobre a proteção da propriedade intelectual de programa de computador, sua comercialização no País, e dá outras providências. $1998 . \quad$ Disponível em: <http://www.planalto.gov.br/ccivil_03/leis/19609.htm>. Acesso em: janeiro de 2022.

CARDOSO, E. E. C; DE DAVID, T. A falta de profissionais de tecnologia de informação no mercado de trabalho, Anais do II Congresso Internacional Uma Nova Pedagogia para a Sociedade Futura: Protagonismo Responsável, p. 697-700, 2016. 
CORDEIRO, D. F.; CASSIANO, K. K. Um panorama do ensino superior em gestão da informação no Brasil. Perspectivas em Ciência da Informação [online], v. 23, n. 4, p. 205-220, ISSN 1981-5344. https://doi.org/10.1590/1981-5344/3617, 2018.

DA SILVA, K. B. Investimentos em TI: Visualização dos Dados do CNPQ. 2021. Trabalho de conclusão de curso (Engenharia da Computação) - Universidade Federal de Santa Catarina, Campus Araranguá, 2021.

FERES, M. V. C; DE OLIVEIRA, J. V.; GONÇALVES, D. D. Robin Hood às avessas: software, pirataria e direito autoral, Revista Direito GV, São Paulo, v. 13, n. 1, p. 69-94, 2017.

FORBES. Apple lidera e Tesla é a que mais cresce em valor de marca global. 2021. Disponível em: <https://forbes.com.br/forbes-tech/2021/10/apple-lidera-e-tesla-e-a-quemais-cresce-em-valor-de-marca-global/>. Acesso em: janeiro de 2022.

PARADA, D. F.; GOLIN, A. L. M. M. A influência da tecnologia da Informação: uma reflexão bibliográfica sobre mercado de TI e organizações. Encontro Internacional de Gestão, Desenvolvimento e Inovação (EIGEDIN), v. 2, n. 1, 2018.

SILVA, L. F. M. Patentes - da bancada para o INPI. 2017. 39 f. Trabalho de conclusão de curso (Bacharel em Química) - Universidade Federal do Rio de Janeiro, Rio de Janeiro, 2017. 